\title{
Autoidentificaciones étnicas de jóvenes de segunda generación de origen mexicano en California
}

\section{Ethnic self-identification of second-generation youth of Mexican origin in California}

Recibido el 19 de mayo de 2020.

Aceptado el 11 de noviembre de 2020.

Publicado el 17 de noviembre de 2020.

*Autora para correspondencia: María del Rosario Narváez Jiménez. Correo electrónico: mariarosarionarvaez@gmail.com

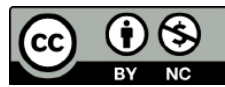

Esta obra está protegida bajo una Licencia Creative Commons Atribución-NoComercial 4.0 Internacional.
María del Rosario Narváez Jiménez ${ }^{\text {a* }}$ (D) https://orcid.org/0000-0002-5151-9123

${ }^{a}$ Universidad Autónoma del Estado de Morelos, Cuernavaca, México, correo electrónico: mariarosarionarvaez@gmail.com

\section{Resumen}

El objetivo de este artículo es explorar las autoidentificaciones étnicas de los jóvenes de segunda generación de origen mexicano. Para ello se toman tres elementos del contexto sociopolítico estadounidense que se encuentra en relación con sus autoidentificaciones, estas son: el propio modelo identitario estadounidense, el imaginario social sobre el mexicano y las categorías censales sobre la etnicidad hispana/latina y la raza. El enfoque biográfico, concretamente la perspectiva etnosociológica de Daniel Bertaux a través de los relatos de vida, ha sido la técnica empleada. La investigación se llevó a cabo durante 2016, en el sur de California donde se entrevistó a 51 jóvenes. Los relatos constatan que algunas de las categorías institucionales llevan a que sean parte de las autoidentificaciones de los informantes, o estos se adjudican muchas de las características fenotípicas y/o raciales que se les atribuyen a dichas categorías. Como limitación se encuentra la imposibilidad de incluir otros relatos.

Palabras clave: autoidentificaciones, segunda generación, relatos de vida, migrantes.

\section{Abstract}

The aim of this article is to explore the ethnic self-identifications of second-generation young people of Mexican origin. To do so, three elements are taken from the American socio-political context that is related to their self-identifications: the identity model of the American, the social imaginary of the Mexican and the census categories of Hispanic/Latino ethnicity and race. The biographical approach, specifically Daniel Bertaux's ethno-sociological perspective through life stories, has been the technique used. The research was carried out during 2016, in Southern California where 51 young people were

CÓMO CITAR: Narváez Jiménez, M. R. (2020). Autoidentificaciones étnicas de jóvenes de segunda generación de origen mexicano en California [Ethnic self-identification of second-generation youth of Mexican origin in California]. Estudios Fronterizos, 21, e062. https:// doi.org/10.21670/ref.2020062 
interviewed. The accounts show that some of the institutional categories end up being part of the self-identifications of the informants, or the informants attribute to themselves many of the phenotypical and/or racial characteristics that are attributed to those categories. The limitation is that it is not possible to include other stories.

Keywords: self-identification, second generation, life stories, migrant.

\section{Introducción}

El objetivo de este artículo es explorar las autoidentificaciones étnicas de los jóvenes de segunda generación de origen mexicano. Para ello se toman tres elementos del contexto sociopolítico estadounidense que se encuentra en relación con sus autoidentificaciones, estas son: el propio modelo identitario estadounidense, el imaginario social sobre el mexicano y las categorías censales sobre la etnicidad hispana/latina y la raza. Los relatos constatan que algunas de las categorías institucionales llevan a que sean parte de las autoidentificaciones de los informantes, o estos se adjudican muchas de las características fenotípicas y/o raciales que se les atribuyen a dichas categorías.

Este trabajo iniciará con un breve acercamiento al tratamiento de la segunda generación desde la teoría de la asimilación y sus variantes, así como de las críticas que más tarde se le hicieron, se destaca la importante aportación de la teoría de la asimilación segmentada. Se continuará con el enfoque teórico-metodológico, el enfoque biográfico, desde la perspectiva etnosociológica de Daniel Bertaux (1999, 2005), donde el relato de vida será la técnica empleada. Seguidamente, se presentarán las características generales del trabajo de campo y de la muestra con la que se trabajó.

En la segunda parte de este trabajo se continuará con una discusión teórica sobre el concepto de identificación étnica y su relación con el surgimiento del Estado-nación moderno. Y para situar la problemática particular, se abordará el imaginario sobre el mexicano en EUA, la categorización censal sobre las diferentes generaciones, así como la delimitación de los mexicanos como grupo étnico y la pregunta sobre la raza. Todo ello se acompañará de fragmentos de relatos de algunos de los informantes que ayudarán a ejemplificar las cuestiones teóricas.

\section{Segunda generación y teoría de la asimilación}

La primera vez que la escuché fue cuando mis primos (en México) me dijeron que era pocha y yo no sabía que era. Y luego pregunté y me dijeron que era cuando una fruta se estropea. Pero la puedes utilizar como algo bonito, con algo con lo que te identificas. Pero, ya, la palabra chicana, de tanto que he aprendido, ya no me identifico con esa. Y tampoco con nomás ser mexicana, o americana [estadounidense]. Ahorita, no sé con qué me identifico [...] con una clase que tomé este verano también aprendí que los hispanos, o los latinos, somos muchos (Alicia, entrevista, 2 de junio de 2016).

El país pionero en la investigación de las migraciones internacionales ha sido EUA, de ahí que las primeras obras en materia de segunda generación, o de hijos 
de inmigrantes, surgieran en este país en la década de 1930, bajo el enfoque de la Teoría de la Asimilación. Entre la literatura que marca el comienzo sobre las segundas generaciones hay que destacar a The Marginal Man, de E. V. Stonequist (1937) que toma como referencia a los hijos de inmigrantes inmersos en el conflicto que resulta vivir entre dos culturas y es donde aparece por primera vez el término de "segunda generación"; en 1938 aparece The problem of the third generation immigrant, de M. L. Hansen, que se centra en el transcurso generacional como medio de asimilación progresiva; pero será hasta 1943, con la monografía Italian or American? de I. L. Child, que se toma como referencia a un grupo específico, los hijos de inmigrantes italianos y en el que la cuestión identitaria comienza a colocarse en primer plano, un nuevo modelo identitario diferente al país de origen de los padres y diferente al del lugar de llegada (García Borrego, 2008). Más tarde, en 1945 aparecería la Teoría de la Asimilación de Warner y Srole, en The Social Systems of American Ethnic Groups (García Borrego, 2008).

Sin embargo, a partir de la década de 1950 la situación cambió, el ascenso social comienza a dificultarse o, simplemente, su pronóstico no se cumple para determinados grupos como el afroamericano (Aparicio, 2007). A partir de entonces, surgen las primeras críticas al modelo asimilacionista. Gordon con su obra Assimilation in American Life (1964) aporta un modelo más complejo basado en la aculturación, la asimilación estructural, y la conformación de una identidad común; mientras que Gans (1979) estableció las diferencias entre los dos modelos de asimilación, Asimilación Lineal y Asimilación en Linea Irregular (García Borrego, 2008). Autores contemporáneos (Alba \& Nee, 1997, 2003; Perlman \& Waldinger, 1997) critican el modelo asimilacionista clásico e incluyen variaciones, pero siguen apostando por el modelo de asimilación. Es importante destacar la propuesta de Portes y Zhou (1993), con la Teoría de la Asimilación Segmentada, que se basa en un modelo representado por una tipología que diferencia entre: 1) la aculturación disonante, 2) la aculturación consonante y 3) la aculturación selectiva.

La teoría de la asimilación segmentada (Portes \& Rumbaut, 2010) parte de un proceso de incorporación abierto y donde el contexto de recepción juega un importante papel, en el que se incluyen las políticas gubernamentales respecto al grupo de origen, las actitudes de la sociedad receptora y los recursos de la comunidad coétnica. Estos son los aspectos que llevan a Portes y Rumbaut (2010) a declarar la situación de los inmigrantes mexicanos y la de sus hijos como la más preocupante. Denominan "el caso mexicano" a la segunda generación de origen mexicano cuyas características "la hacen única". Los mexicanos constituyen el grupo de extranjeros más numeroso y con mayor antigüedad, de ahí que su segunda generación sea también la más numerosa e incluso que cuente con una tercera. Ello es consecuencia de la contigüidad geográfica entre ambos países, lo que ha permitido un flujo continuo de mano de obra. La relativa facilidad de estos movimientos explica un menor capital humano en comparación con otros colectivos de inmigrantes procedentes de países aún más pobres. Esto ha provocado que debido a su número, su pobreza y su visibilidad hayan sido el blanco de políticas dirigidas, específicamente, para dificultar su entrada al país y para repatriar a los que ya estaban; lo que ha originado un contexto de hostilidad que ha influido en la precariedad laboral y en modos de incorporación negativa. Por tanto, las consecuencias que se pueden esperar bajo estas circunstancias no son nada halagüeñas, como así lo demuestran los resultados de sus investigaciones. 


\section{Enfoque biográfico: relatos de vida}

El enfoque biográfico, concretamente los relatos de vida desde la perspectiva etnosociológica de Daniel Bertaux (2005), ha sido el encuadre desde el que se ha llevado a cabo el análisis y la interpretación de los datos. Bertaux (1999) parte de la diferenciación que en lengua inglesa se hace entre los términos life story, relato de vida, y life history, historia de vida. Toma como referencia la propuesta de Norman K. Denzin (1970), quien basándose en esta distinción comprende cada uno de estos términos de la siguiente manera: life story o relatos de vida que se refiere a "la historia de una vida tal como la cuenta la persona que la ha vivido". Mientras que el segundo, life history o historia de vida, comprende "los estudios de casos sobre una persona" "incluyendo no solo su propio relato de vida, sino también otras clases de documentos" como "la historia clínica, el expediente judicial" "los testimonios de allegados, etcétera" (Bertaux, 1999, p. 3). Denzin se posiciona a favor de la opción de enfoque biográfico, pues de esta manera se asume "la adopción de una nueva técnica", pero también "la construcción paulatina de un nuevo proceso sociológico" (Bertaux, 1999, p. 3), "de un nuevo enfoque" donde se concilian "la observación y la reflexión” (Bertaux, 1999, p. 4).

Para la perspectiva etnosociológica, los relatos de vida son entendidos como una de las formas de expresión de la experiencia humana (Bertaux, 2005). Se "considera al interlocutor como un informante" (Bertaux, 1999, p. 10) y al relato, la narración que una persona hace de su propia experiencia de vida. Se trata de una autobiografía, ya que es la persona quien narra su vida. Así, el relato tiene lugar a través del diálogo que se produce entre el sujeto y el investigador; por lo que se produce a petición del investigador, quien tendrá unos intereses de conocimientos particulares sobre dicha experiencia, que se limita a uno o varios ámbitos del todo de esa experiencia de vida.

El objetivo central del relato de vida será reflejar la estructura diacrónica de la experiencia vital, a través de la narración de la experiencia vivida. De esta manera, la entrevista se ha enfocado desde el propio curso de vida con el propósito de poder conocer cómo se ha desarrollado la experiencia vital del joven, desde la infancia, que pasa por el comienzo de la juventud y su evolución durante esta etapa hasta la actualidad. Por tanto, aunque la perspectiva etnosociológica se inspira en la tradición etnográfica, sus objetivos se construyen con base en un matiz sociológico. Esto es, "un tipo de investigación empírica basada en el trabajo de campo, inspirado en la tradición etnográfica para sus técnicas de observación, pero que construye sus objetivos por referencia a ciertas problemáticas sociológicas" (Bertaux, 2005, p. 15). Mientras que la etnografía será entendida como un modo de hacer interpretación de lo que otros cuentan y de las propias observaciones del investigador. Serán interpretaciones de interpretaciones, es decir, interpretaciones "de segundo y tercer orden" (Geertz, 1973, p. 28) y concebidas como ficciones por tratarse de algo que ya está hecho, pero que no hay que confundir con lo ficticio.

Al seguir el procedimiento de la perspectiva etnosociológica, se ha partido del análisis e interpretación interna de los relatos, así como de la comparación de casos variados, con el objetivo de generalizar, de realizar una transición desde lo particular a lo general, procedimiento característico del modelo inductivo. El procedimiento ha consistido en la comparación de diversos relatos de vida, con el fin de elaborar conceptos y categorías como resultado del proceso de interpretación. Así, cada relato ha sido interpretado como parte del conjunto que suponen los relatos de vida de los 
jóvenes de segunda generación de origen mexicano en el sur del estado de California. De esta manera, los conceptos y categorías resultantes han ayudado a la elaboración de "hipótesis plausibles".

Esta forma de proceder se distancia del modelo de investigación hipotético deductivo, que se caracteriza por partir de lo general para desembocar en lo particular, se desarrolla mediante la verificación de hipótesis y cuyo objetivo es la explicación; ello, a su vez, repercute en la construcción de la muestra, ya que no se trata de una muestra estadísticamente representativa, sino que se ha construido de manera progresiva, a la par de la recogida de datos y de la búsqueda de semejanzas y diferencias entre los distintos casos a comparar. Este es el procedimiento de la Teoría Fundamentada de Glasser y Strauss, cuya propuesta reside en el método de la comparación constante y en el muestreo teórico, así como en la obtención de los datos que proceden de la realidad observada y registrada.

\section{Trabajo de campo y características de la muestra}

Con el fin de delimitar la población integrante de la segunda generación se ha tomado como referencia la propuesta de Rubén G. Rumbaut (2006), quien diferencia entre "primera generación", integrada por los nacidos en el extranjero y que subdivide en las generaciones: $1.75,1.5$ y 1.25, en función de la edad de llegada al nuevo país. Y la "segunda generación" que incluye a los nacidos en eUA e integra a las generaciones 2.5 y 2.0. En este trabajo se considerará a los jóvenes nacidos en EUA y a los nacidos en el extranjero integrantes de la segunda generación, ya que muchos de estos últimos, debido a la temprana edad a la que llegaron a EUA, han tenido un proceso de socialización similar al de los nativos.

El trabajo de campo se ha desarrollado en el sur del estado de California, concretamente en los condados de Orange y Los Ángeles, los más poblados y con una importante proporción de población de origen mexicano; durante un periodo de seis meses, comprendido entre marzo y agosto de 2016. Los jóvenes entrevistados ${ }^{1}$ fueron 51, de ellos 24 son mujeres y 27 son hombres, con edades comprendidas entre los 16 y 36 años. En cuanto a la generación, 32 jóvenes pertenecen a la generación 2.0, es decir, nacieron en EuA, la mayoría en el estado de California; mientras que los 19 restantes son migrantes, de los que 10 pertenecen a la generación $1.75,5$ a la generación 1.5 y 4 a la generación 1.25 . Y en cuanto a sus estatus legales: 11 cuentan con residencia permanente o ciudadanía, mientras que de los otros 13,7 se encuentran bajo la protección de DACA (Deferred Action for Childhood Arrivals) y 6 están indocumentados.

\footnotetext{
${ }^{1}$ La transcripción de los relatos se ha llevado a cabo de manera literal con el fin de plasmar, del modo más realista posible, la forma en que se produjeron los discursos, mientras que el nombre de los informantes se ha cambiado con el fin de mantener el anonimato.
} 


\section{Autoidentificación étnica}

La identificación es "el proceso de sujeción a las prácticas discursivas, y la política de exclusión que todas esas sujeciones parecen entrañar" (Hall, 1996, p. 15). Entre sus cualidades destacan su permanente construcción, su carácter estratégico y "posicional" y su preocupación por la demarcación de "la diferencia", los "límites simbólicos" y la "producción de fronteras" (Hall, 1996, p. 16). Al mismo tiempo, los procesos de identificación necesitan del reconocimiento de los sujetos con los que se interactúa. En este sentido, Hall (1996) alude a la relación de alteridad como principal componente de las identidades. Donde no ha de tratarse solo de las diferencias establecidas, sino también de las desigualdades que implican y de sus consecuencias, como la discriminación y la exclusión.

En el caso de los jóvenes de segunda generación de origen mexicano entrevistados para este trabajo, el componente étnico es una constante en sus relatos. En sus autoidentificaciones, referencias a las categorías de latino, méxico-americano o chicano, entre otras, están presentes. Se trata de categorías institucionalizadas por el gobierno estadounidense, referidas a la población mexicana y/o de origen mexicano con las que los jóvenes de segunda generación se identifican, ya sea porque han migrado desde México o porque sus padres o antepasados lo hicieron. Por tanto, sus argumentos coinciden con otra característica de las identificaciones como son las cuestiones referidas "al uso de los recursos de la historia, la lengua y la cultura" (Hall, 1996, p. 17), en función del futuro y de las múltiples posibilidades que ello puede ofrecer de llegar a ser; es decir, "cómo nos han representado y cómo atañe ello al modo como podríamos representarnos" (Hall, 1996, p. 18). De esta manera, el principal aspecto que caracteriza las autoidentificaciones de los informantes en su definición con base en las relaciones de alteridad mantenidas con ese otro "anglo". Este proceso de construcción sobre quiénes son ellos, entendido como "nosotros", frente al "otro", puede ser entendido como:

Laidentificación étnica comienza con laaplicación de una etiqueta determinada a uno mismo dentro de un proceso cognitivo de autocategorización que conlleva no solo la reivindicación de la pertenencia a un grupo o a una categoría, sino también un contraste diferenciado entre la categoría o el grupo propio y otros grupos y categorías (Portes \& Rumbaut, 2010, p. 189).

Y su importancia reside en que:

El modo en que esos jóvenes se definen a sí mismos es significativo, pues revela mucho acerca de sus adscripciones sociales y de cómo y dónde creen que encajan en una sociedad de la que son sus miembros más recientes (Portes \& Rumbaut, 2010, p. 191).

De esta manera, la etnicidad integra la cuestión del "nosotros" y "ellos", es decir, la separación y, al mismo tiempo, la reunión de la población en relación con estas dos categorías. Se trata de "una cuestión de clasificación", de "separación y reunión de la población en una serie de categorías definidas en términos de 'nosotros' y 'ellos"” (Epstein, 2006, p. 91). Asimismo, los Comaroff (Comaroff \& Comaroff, 1992) sostienen que la etnicidad como adscripción también parte de una relación de oposición, una relación de otredad, cuya importancia reside en la relación que se establece y que está 
basada en el principio de otredad. Estas categorizaciones suelen basarse en la creación de "diferencias culturales" que funcionan como argumentos con los que se justifican las desigualdades; al mismo tiempo que se convierten en la base del establecimiento de relaciones asimétricas y en el origen de la conciencia étnica. De ahí que lo que Epstein (2006) destaca de la identidad étnica es que la etnicidad es uno más de los múltiples factores que conforman la identidad; sin embargo, la etnicidad agrupa al resto de estatus y roles con los que cuenta el individuo, y es precisamente esta integración lo que la convierte en "identidad terminal". Por tanto, su importancia reside en su función como eje estructurador de las relaciones sociales, lo que acaba determinando el resto de los roles y estatus; así como las categorizaciones de "nosotros" y "ellos", como efecto de las relaciones de alteridad. Todo ello dará como resultado el establecimiento de categorías sociales que constituirán el origen de las identidades étnicas.

Mauricio, 26 años, generación 2.0:

- ¿Cómo te sientes ahora, desde el punto de vista identitario?

- ¿Cómo me clasificaría? Am... esos sí son también una genery, son un camino grande porque antes, cuando era joven, yo era "americano"; y después, cuando estaba en la preparatoria, era "mexican-american". Y cuando entré al colegio era "chicano", pero con una ch, chicano. Cuando me gradué era como una $\mathrm{x}$, Xicano, para reconocer el grupo de..., indígena. $\mathrm{Y}$ ahora, creo, me gusta más "pocho". Antes que nada, porque antes me decían pocho en México y no me entendían. Me decían pocho aquí, y no me entendían y..., ya, de rato, me dijo, gente de aquí, que no son de aquí ni de allá, no muy mexicano y andan allá haciendo cosas americanas. Y... como vi el término chicano, empecé a entender que pocho era lo mismo, que era como un insulto que alguien le estaba tirando a mí. Pero en realidad, pocho ¿qué es? Es más así como me identifico ahorita (Mauricio, entrevista, 23 de mayo de 2016).

El caso que se acaba de exponer refleja un proceso de autoidentificación complejo y cambiante. Este evoluciona desde categorías asimilacionistas como la de "americano", con la que se identificaba al inicio de su juventud, hasta categorías étnicas como las de chicano o pocho. La resignificación es el elemento que marca la tónica del relato, así queda reflejado en el ejemplo del término "pocho" que se origina como un concepto peyorativo, pero Mauricio explica por qué y cómo lo resignifica y cómo acaba apropiándose del mismo. Pero además, este término pocho marca una doble exclusión, ya que, como afirma, suele ser un término atribuido a alguien que no es "de aquí ni de allá”. De esta manera, su relato refiere la relación que muchas identidades tienen con un lugar, con un territorio demarcado social y políticamente como el del Estado-nación, que va asociado a una comunidad cultural y/o grupo étnico que definirá su identidad, como se verá a continuación. 


\section{Los Estados-nación modernos y el origen de la etnicidad}

Para la teoría de la modernidad, la aparición del Estado-nación moderno ${ }^{2}$ traerá consigo la idea de nacionalismo y etnicidad (Wimmer \& Glick Schiller, 2002). La idea de nación que surge a raíz de esta nueva forma de organización política es la de un conjunto de personas que comparten un origen histórico común con base en aspectos culturales, lingüísticos e identitarios. Con el concepto de Estado se hace referencia a un sistema de gobierno que rige dentro de un territorio delimitado. Por tanto, el surgimiento del Estado-nación aparece asociado a unos límites territoriales que demarcarán sus fronteras, al mismo tiempo que funcionarán como contenedores de la sociedad. $Y$ las sociedades que surgen como consecuencia del proyecto moderno lo harán bajo un conjunto de rasgos culturales y lingüísticos que definirán su identidad.

De esta manera, se establece el nacionalismo imaginario en referencia a la comunidad imaginada de Benedict Anderson, que, además, será delimitado por unas fronteras físicas, límites reales que separarán a los de adentro de los de afuera, a los nacionales de los extranjeros. Así, los inmigrantes y las minorías étnicas se convierten en la amenaza de los Estados ya que son considerados lo opuesto a la idea de nación, motivo por el cual deben ser asimilados por el Estado. Por tanto, el proyecto nacional moderno reúne un conjunto de elementos referidos a aspectos tan diversos como la cultura, la economía o la seguridad, entre otros; que conlleva que la etnicidad sea entendida desde los aspectos culturales, en relación con la idea de nación y a la inclusión, y/o exclusión, que ello supone; así como desde los aspectos socioestructurales por las consecuencias que dicha inclusión y/o exclusión conllevan (Epstein, 2006; Comaroff \& Comaroff, 1992).

En el caso que se presenta a continuación, la joven no tiene dudas en cómo autoidentificarse, se considera mexicana porque nació en México.

Sara, 22 años, generación 1.5 (llegó con su madre cuando tenía 8 años):

— Siempre pongo [...] latino o hispano. ¡Ajá! [...] aunque mis amistades me dicen: "pero es que tú no te pareces mexicana" [...] pero sí lo soy. O sea, yo nací en México (Sara, entrevista, 25 de mayo de 2016).

\section{El imaginario sobre el "mexicano" y algunas de sus consecuencias}

La visión estereotípica y negativa de la población latina en general, y de la mexicana en particular, está presente en los relatos de los jóvenes. Este imaginario fue estandarte de la campaña presidencial de Donald Trump, pero se trata de un discurso que ha estado presente desde antaño; incluso, ha protagonizado algunas de las polémicas de determinados intelectuales estadounidenses, como la de Samuel Huntington, en su obra Who Are We? The Challenges to America's National Identity. El controvertido autor de

\footnotetext{
${ }^{2}$ Aunque desde el punto de vista de Hanna Arendt (2009), EUA no puede ser considerado un Estado-nación, los objetivos de sus políticas asimilacionista actúan acorde a los del Estado-nación. Pues persiguen la equiparación de la "ciudadanía" con la "nacionalidad", entendida como una comunidad constituida por elementos comunes como: la etnia, la raza o la lengua, entre otros aspectos.
} 
El Choque de Civilizaciones muestra su preocupación por el aumento de la población hispana en EUA, a la que concibe como el mayor enemigo de la sociedad estadounidense dentro de sus fronteras. Su preocupación reside en si Eua continuará siendo un país con una sola lengua nacional y una cultura básica angloprotestante; o si, por el contrario, se cumplirá su peor pesadilla, que se convierta en un país con dos "culturas", la anglo y la hispana, y dos lenguas, el inglés y el español (Durand, 2017). Los argumentos de Huntington ${ }^{3}$ contribuyen a esclarecer el nacionalismo estadounidense, así como la ideología en la que se sustentan las políticas asimilacionistas desarrolladas a lo largo de su historia. No duda en afirmar que EuA fue creada por "colonos fundamentalmente blancos, británicos y protestantes" que con su cultura e instituciones constituyeron la base de lo que hoy es este país, además de que la raza, la etnia, la cultura y la religión, y más tarde también la ideología, fuesen los elementos que lo definieron (Huntington, 2004, p. 1).

Por consiguiente, el blanco, anglosajón y protestante (WASP, white, anglo-saxon and protestant), base de la identidad nacional, se encuentra "amenazado", cada vez más, por la diversidad y por identidades sustentadas en grupos étnicos. Pero sin lugar a duda, la mayor amenaza es la representada por sus vecinos del sur, los inmigrantes procedentes de Latinoamérica y, particularmente, por los mexicanos y sus descendientes, la segunda generación.

Ramón, 30 años, generación 2.0:

- Ahí fue donde yo conocí el primer americano y armenio, y ruso [se refiere a la nueva preparatoria]. ¿Qué es esto? ¡Yo no conozco rusos! Yo ni sabía quién era aquí [...] (Porque ¿tú antes ibas más, con latinos, a la escuela?) [...] eran todos latinos y filipinos, y morenos. So, nomás. Y cuando yo fui al high school, ¡oh yeah!, ahí sí fue [...] comencé a sentir discriminado, porque yo nomás conocía [...] piel morena [...] y yo digo: ¡wow, qué diferente! Ahí sí me sentí solo (Ramón, entrevista, 5 de junio de 2016).

Para Ramón, el aspecto identitario se evidencia en el color de su piel e implica una cuestión de diferencia, que se hizo más explícita cuando, además, se transformó en discriminación. Esta experiencia que se inició tras su llegada a la nueva preparatoria, después de un cambio de centro educativo que también produjo un cambio de contexto social. A partir de este evento fue consciente de que su origen, y el de su familia, implicaba no solo diferencia, sino también discriminación y desigualdad. Pues sus amigos de la preparatoria pertenecían a orígenes étnicos diferentes y a estatus socioeconómicos más altos. La pertenencia de su familia a un estatus socioeconómico mucho más bajo se traducía en la desigualdad que percibía respecto a sus nuevos compañeros. Por tanto, los cambios desencadenados tras su cambio de centro educativo se tradujeron en un cúmulo de nuevas experiencias y vivencias, a las que se refirió en otra parte de la entrevista como "una crisis de identidad".

La experiencia de Ramón refleja la visión negativa que la sociedad estadounidense (caracterizada como blanca, anglosajona y protestante —wASP-) tiene de ellos, los mexicanos, considerados como el "otro", es decir, el no blanco, hispano/latino y católico. Su relato refleja un sentimiento de diferencia frente al estadounidense, así

3 "El reto hispano" (Huntington, 2004) es un extracto del capítulo 9 del libro Who Are We? The Challenges to America's National Identity. 
como la desigualdad que esta definición de "otro" lleva aparejada, pues es consciente de que la diferencia entre sus nuevos compañeros y él no solo es fenotípica y/o racial, sino también social. De ninguno de estos aspectos se había percatado previamente, ya que hasta entonces solo se había relacionado con pares de su mismo origen étnico o similar, lo que demuestra, al mismo tiempo, la segregación socio-espacial ${ }^{4}$ característica de las ciudades estadounidenses.

La importancia que Ramón, así como otros informantes, otorgan al color de piel está relacionada con la relevancia que los aspectos fenotípicos y/o raciales han tenido en la conformación de la sociedad estadounidense (Omi \& Winant, 2015). De ahí que constituyan categorías institucionalizas recogidas en el censo del país. Y como reconocía Ramón, no se trata solo de diferencias fenotípicas y/o raciales sino de las desigualdades sociales que lleva aparejadas. De ahí que Omi y Winant (2015) conciban a la raza como un concepto que representa conflictos e intereses sociales de diferentes cuerpos humanos, lo que equivaldría a decir que estos cuerpos representan diferentes grupos sociales.

\section{Clasificación del Censo de Estados Unidos de América: categorías generacionales}

Los censos llevan a cabo el recuento de los miembros que conforman la población de un Estado, además, con el fin de conocer algunas de sus características, elaboran preguntas que permiten clasificar y conocer determinados aspectos tanto de sus ciudadanos como de los extranjeros que se encuentran residiendo legalmente en el país. Entre las más básicas se encuentran las referidas al sexo, la edad o el lugar de nacimiento, entre muchas otras. Pero por el tema aquí tratado, se tomarán aquellas cuyo criterio básico es el lugar de nacimiento. De esta manera, el Censo de EuA clasifica a la población según el lugar de nacimiento diferenciando entre "extranjeros" y "nativos", categorías principales de las que derivarán: "primera generación”, "segunda generación" y "tercera y más generación".

Con el fin de comprender a qué se refiere y a quiénes incluye, o excluye, cada una de las categorías, se empezará por la primera, "extranjero", ${ }^{5}$ que es toda aquella persona que no es ciudadano estadounidense de nacimiento. ${ }^{6}$ En cambio, "nativo" será cualquiera que haya nacido en EuA, Puerto Rico, o en el área de las islas de Guam, Samoa Americana, Islas Virginias, Commowealth del norte de las Islas Marianas, o todos aquellos nacidos en el extranjero con al menos uno de los padres ciudadano estadounidense. Las tres categorías restantes del conjunto (primera, segunda y tercera generación y más) serán especificaciones de las dos anteriores. Así, bajo el concepto de "primera generación" se incluirá a todos aquellos nacidos en el extranjero, es decir, se

${ }^{4}$ Segregación social que lleva aparejada, a su vez, "la segmentación del sistema educativo" (Saraví, 2015).

${ }^{5}$ La información sobre las diferentes categorías generacionales se ha obtenido de Trevelyan y colaboradores (2016).

${ }^{6}$ Incluye a ciudadanos naturalizados, a residentes permanentes legales, a inmigrantes temporales (así como a estudiantes extranjeros), a inmigrantes humanitarios (como refugiados) y a inmigrantes indocumentados. 
trata de un concepto intercambiable con el de extranjero. La "segunda generación" se referirá a los nativos, esto es, a toda aquella persona nacida en EUA o en sus territorios no incorporados, con al menos uno de los padres nacido en el extranjero. Y por último, "la tercera generación y más" que se refiere al "estadounidense", toda persona nacida en EUA o en sus territorios no incorporados, con ambos padres nativos. Por tanto, estas dos últimas categorías funcionarán como especificaciones de los nativos, cuya diferencia básica reside en el distanciamiento de los ascendentes extranjeros por línea directa, de uno o dos, respecto a los padres, en el caso de la segunda generación. Y de ninguno para la tercera y más generación ya que los ascendentes más cercanos serán los abuelos.

Como resultado de la clasificación censal, la población de origen mexicano queda divida en tres grupos: "migrantes mexicanos", donde se incluye a las personas que migraron desde México a EuA y que serán incluidos en la categoría de extranjeros o primera generación. En segundo lugar, jóvenes nacidos en EuA y con al menos uno de los padres nacidos en México, que integrarán "la segunda generación". Y jóvenes de "tercera y más generación", que serán todos aquellos nacidos en EUA y cuyos padres también son nacidos aquí (en EUA).

A través de esta clasificación se pueden extraer dos conclusiones, la primera es la diferenciación básica que realiza cualquier Estado entre ciudadanos y extranjeros, que hace referencia a un conjunto de aspectos políticos, sociales y culturales; pero también de derechos y obligaciones que establecen diferencias y desigualdades entre ambos estatus. Y la segunda, la diferenciación mediante generaciones que parece tener una base genético-cultural que toma como referencia la distancia de los ancestros extranjeros, mediante la que, poco a poco, se llegará a ser "estadounidense". Pues así es definida la tercera y más generación, el "estadounidense", el nativo y con ambos padres también nativos.

El caso que se presenta a continuación es un claro ejemplo de la clasificación censal, ya que el informante hace referencia a la cuestión generacional mediante las relaciones de filiación, entre otros aspectos. Alude al propio argumento utilizado por el censo, donde no es hasta la tercera generación que una persona puede ser considerada "estadounidense".

Rubén, 21 años, generación 2.0:

- En mi opinión, un chicano es una persona que tiene padres que son de México, pero vinieron para acá $[\ldots]$ sí, yo creo que soy chicano porque mis padres nacieron en México y vinieron para acá [...] entonces, nací aquí y hablo inglés y español.

- ¿Americano y chicano son diferentes?

— En que americano y chicano están nacidos aquí, en América, en los Estados Unidos. En mi opinión es que yo no soy [...] gringo, no soy blanco [...] mis padres no nacieron aquí, aquí, por generación-generación como ellos (los gringos). Yo me siento mexicano o chicano. Aunque nací aquí, yo me miro [...] brown. Hay un montón de categorías aquí [...] no es algo bueno [...] “you're labeling on yourself" (Rubén, entrevista, 3 de mayo de 2016).

Rubén, además de hacer referencia a la relación de filiación respecto a sus padres, quienes migraron desde México, introduce otros dos aspectos, la lengua y el color de piel como aspectos que diferencian a los mexicanos de los "gringos". El español que 
hablan los mexicanos, frente al inglés de los anglos; este es un aspecto mediante el que se pueden asimilar fácilmente a través del aprendizaje de la nueva lengua, sobre todo los jóvenes que han sido socializados y escolarizados en EUA. Es importante mencionar que la escuela es una de las principales instituciones de socialización, sobre todo la estadounidense, que tiene en la lengua la principal herramienta de asimilación. En cambio, el color de piel, "Brown" frente al "White" american, es una marca que permanece, incluso, con el paso de las generaciones. Por tanto, se trata de dos aspectos que veremos a continuación y que también están recogidos en el Censo de EuA mediante la pregunta sobre el origen latino/hispano y la dirigida a la cuestión racial.

\section{Etnicidad y raza en el Censo de Estados Unidos de América}

El Censo de eua también incluye una pregunta sobre el origen étnico hispano/ latino y otra sobre la cuestión racial. La pregunta relativa al origen étnico ${ }^{7}$ se dirige, exclusivamente, a un grupo étnico en particular, el hispano o latino: "Is this person of Hispanic, Latino, or Spanish origin?". ${ }^{8}$ El censo aclara que el origen "hispano/latino" ${ }^{9}$ es visto como una herencia, nacionalidad, linaje o país de nacimiento de la persona, de sus padres o de los ancestros anteriores a su llegada a EUA; y no implica una categorización racial. Las respuestas a esta pregunta son autoidenficaciones por parte de los censados. De esta manera, las personas categorizadas de origen mexicano, ${ }^{10}$ méxico-americano y chicana, entre otros, lo son con base en su propia identificación. Por tanto, el criterio que rige esta clasificación es la propia identificación como hispano/latino, sin distinciones entre extranjeros y nativos, ni entre generaciones.

La importancia de las categorizaciones y particularmente de la pregunta sobre el origen hispano/latino reside, como afirma Epstein (2006), con base en Barth, en que la etnicidad comienza con la atribución de categorías sociales. De ahí que lo fundamental sea el significado que tiene la pertenencia a la categoría "hispano/ latino". Lo más plausible es entender esta categoría como grupo étnico, como "una comunidad que" "se perpetúa biológicamente"11 y que además "comparte valores culturales fundamentales", "integra un campo de comunicación e interacción” y sus "miembros" "se identifican a sí mismos y son identificados por otros", lo que los convierte en "una categoría distinguible de otras categorías del mismo orden" (Barth, 1976, p. 11). Ello implica un claro "límite étnico" (Barth, 1976, p. 17) entre ser, o no, hispano/latino.

${ }^{7}$ Esta pregunta ha estado presente en los últimos cinco censos realizados. Fue probada por primera vez en 1969, y más tarde se incorporó en el censo de 1970. Pero fue hasta 1980 que se introdujo la denominación "hispanic", que sustituyó al de "spanish". En el censo de 2010, la pregunta era formulada de la siguiente manera: Is this person of Hispanic, Latino, or Spanish origin?

${ }^{8}$ La información referente al origen hispano/latino se ha obtenido en (Ennis et al., 2011).

${ }^{9}$ El término "hispano o latino" se refiere a personas procedentes de Cuba, México, Puerto Rico, América Central o del Sur, o de otra cultura española u origen, independientemente de la raza.

${ }^{10}$ Los que se identifican de origen mexicano pueden ser personas nacidas en México, EUA o en algún otro país. Y lo mismo ocurre para el resto de los orígenes nacionales.

${ }^{11}$ Aunque las definiciones de grupo étnico tienden a hacer referencia a los aspectos culturales que definen a un conjunto de personas, se ha preferido esta definición porque se entiende que la categorización de hispanos/latinos, además del origen, lleva implícita un componente étnico y fenotípico. 
Precisamente, el origen étnico con base en el linaje es el argumento que sustenta la siguiente informante para justificar su mexicanidad. Para Selene "ser mexicana" está asociado a una cuestión genética, ya que, como afirma, está en su "sangre", en referencia al origen nacional de sus padres.

Selene, 19 años, generación 2.0:

- Yo pongo méxico-americano.

- ¿Y por qué pones esa opción?

- Porque así me siento. Soy mexicana, no por ser nacida aquí, yo voy a decir:

"soy gringa" $[\ldots]$ es lo que está en mi sangre, mis raíces $[\ldots]$, soy mexicana [...] de padres mexicanos (Selene, entrevista, 16 de mayo de 2016).

En cuanto a la cuestión racial, ${ }^{12}$ el Censo ${ }^{13}$ también incluye una pregunta referida al origen racial de las personas. Así, la pregunta 6 se formula de la siguiente manera: "What is this person's race?". Al igual que hace con la categoría de origen étnico hispano/ latino, también aquí se encarga de aclarar que la categoría raza ${ }^{14}$ refleja una definición social reconocida en el país y que no pretende definir la raza desde el punto de vista biológico, antropológico o genético. Es por ello por lo que la pregunta incluye raza y origen nacional de los grupos socioculturales. ${ }^{15}$ Las respuestas también se basan en las autoidentificaciones y da la posibilidad de elegir entre más de un grupo racial. Por tanto, la pregunta sobre el origen hispano o latino no excluye el origen racial, de manera que los hispanos/latinos, además de su origen étnico, deberán marcar el grupo racial específico con el que se autoidentifican.

En segundo lugar, la pregunta sobre la raza, con excepción de las categorías de "blanco" y "negro", hace referencia en mayor medida a las nacionalidades. Incluye

\footnotetext{
12 La información sobre la cuestión racial se ha obtenido en Rastogi y colaboradores (2011) e Hixson y colaboradores (2011).

${ }^{13}$ Según el censo, las razones por las que se llevan a cabo estas preguntas son con el fin de obtener información, que permita el cumplimiento de determinados objetivos, como el cumplimiento de determinadas leyes y requerimientos de programas. Entre ellos, se hace referencia al uso que le dan los estados a esta información, en cuanto al monitoreo de las jurisdicciones locales en relación con el derecho al voto y su utilidad para la toma de decisiones políticas. El beneficio que puedan suponer para las personas, las familias y las comunidades, ya que esta información es necesaria para incrementar y evaluar programas o hacer cumplir leyes, como el derecho al voto u oportunidades de igualdad en el empleo. La utilización que las organizaciones públicas y privadas puedan hacer de los datos, con el fin de implementar servicios con base en necesidades especiales, así como para la planeación e implementación de programas de educación, alojamiento, salud y otros, en relación con las necesidades específicas que se detecten.

${ }^{14}$ La categoría racial "blanco" incluye a los que responden entradas como caucásico o blanco, así como árabe, libanés y palestino; y los que contestan norteafricanos, como argelinos, marroquíes y egipcios. Y la categoría "negro o afroamericano", se refiere a una persona que tiene orígenes en cualquiera de los grupos raciales negros de África. Esta categoría incluye a las personas que marcan las opciones de negro, afroamericano o negro; así como a los que responden africanos subsaharianos, kenianos y nigerianos; afrocaribeños, haitianos y jamaicanos. Los africanos subsaharianos son clasificados como negros o afroamericanos, con la excepción de los sudaneses y los caboverdianos debido a sus complejas herencias históricas.
}

${ }^{15}$ En el censo de 2010 se añadieron ejemplos a las opciones de otros asiáticos y otras islas del Pacífico. 
entre sus opciones, raza y origen nacional de los grupos socioculturales, ${ }^{16}$ lo que lleva a pensar que se acaba categorizando, además de por origen racial, por origen nacional. Por otro lado, como se ha expuesto previamente, la referencia al origen étnico puede ser entendida como grupo sociocultural. Por tanto, la diferencia entre las categorías de hispanos/latinos y las de los "grupos socioculturales" que aquí aparecen recogidos es que respecto a estos últimos no se toma en cuenta la cuestión generacional. ${ }^{17}$

De esta manera, las clasificaciones del Censo de EuA constituyen un conjunto de categorías que toman como referencia el lugar de nacimiento y las relaciones filiales, con las que se establecerán las subcategorías generacionales. Mientras que las referencias "étnicas" y/o "raciales" establecerán, a su vez, diferencias con base en el "origen" propio y/o de los ascendentes, así como en cuanto a las atribuciones raciales.

Nuevamente, en los casos que se presentan a continuación, los informantes hacen referencia a algunas de las categorías oficiales recogidas en el Censo de EuA. Sus autoidentificaciones coinciden con categorías cuya característica definitoria principal es la relación de alteridad establecida con el "gringo" o "americano" blanco; así como con la cuestión generacional de sus ancestros que contribuye a la definición del propio origen étnico como "mexicano" o "latino", aunque se haya nacido en EUA. Por tanto, las cuestiones fenotípicas y/o raciales están presentes de manera explícita en sus autoidentificaciones.

Yaretzi, 27 años, generación 2.0:

- Yo me identifico como mexicana. Ah... porque hay aplicaciones... no hay otras opciones. Te dan: "white american, mexican, african american". Y yo no soy, no soy gringa. Fui nacida aquí, pero mis papás son mexicanos. So, yo siempre he elegido mexican $[\ldots]$ hay aplicaciones onde te ponen si eres: latina, mexicanamerican y es cuando selecciono esa opción.

- ¿Y por qué no pones americana, si tú eres de aquí?

- Porque dice: "white-american" [...] I mean, yo soy americana, yo fui nacida aquí [...] You know? [...] pero no soy White (Yaretzi, entrevista, 20 de abril de 2016).

Mauricio, 26 años, generación 2.0:

- Cuando tienes que llenar una aplicación [...] ¿cómo te categorizas?

- Creo que white, que es güero, like, native-american [...] el estado de Califormia, por su historia, los mexicanos [...] eran güeros [...] es algo complicado... Entonces, yo ponía white, porque es lo que tenía. Pero, ahorita, pongo native-american, que es indio.

- ¿Indio americano?

- Ajá. Nativo americano (Mauricio, entrevista, 23 de mayo de 2016).

Respecto al uso de la categoría "nativo americano", Mauricio le atribuye, precisamente, su significado literal, originario de EUA, razón por la cual elige esta opción en las aplicaciones. Sin embargo, ello no la convierte en su categoría de

\footnotetext{
${ }^{16}$ Los únicos grupos raciales o socioculturales, incluidos explícitamente en las opciones, son: los nativos americanos, los nativos de Alaska, los Hmongs y los Laotianos. Estos dos últimos son los únicos que no aparecen asociados a ningún origen nacional concreto.

${ }^{17}$ El origen hispano/latino se refiere a la herencia, a la nacionalidad, al lugar de linaje o país de nacimiento de la persona o de sus padres y/o ancestros (Ennis et al., 2011).
} 
referencia, pues como expresó en otro fragmento de su relato expuesto previamente, se identifica como "pocho", lo cual constituye un término despectivo que se atribuye a los mexicanos que migraron a EUA o a sus hijos, con lo cual está asociado a un origen nacional concreto, México; en cambio, el significado que le da Mauricio es el de "alguien que no es ni de aquí ni de allá". Como él mismo argumentaba, era el apodo con el que se refería a él cuando viajaba a México. Por tanto, ello nos muestra la discriminación y exclusión a la que se han enfrentado muchos de los jóvenes durante sus visitas a México, como algunos de ellos han indicado.

En definitiva, la incorporación de la pregunta sobre el origen étnico dirigida a la comunidad latina/hispana, así como la pregunta sobre la raza constituyen algunos de los mecanismos que los Estados-nación utilizan para excluir a las minorías y/o grupos étnicos a los que considera externos, por ser constituidos como "otro", como en el caso de los mexicanos, y/o por representar un modelo identitario diferente al ideal nacional. A estos mecanismos Mercado (2013) los denomina de "ciudadanía sustractiva", ya que aparta, separa a los grupos que no entran dentro del ideal de "americano". Como se ha visto, los jóvenes entrevistados no se consideran "americanos", a pesar de que hayan nacido en EUA o hayan pasado la mayor parte de su vida ahí.

\section{La indigeneidad como doble estigmatización y como relación simbólica}

Como se ha reflejado en los relatos de los jóvenes, la visión estereotípica del mexicano ha sido una constante. Sin embargo, el caso de Sebastián es diferente, ya que ha sufrido un doble proceso de estigmatización debido a su condición de "indio" en México y en eua. Su relato es un ejemplo del "modelo de homogeneización étnico" promovido por "las élites gubernamentales" mexicanas que tuvo lugar en el pasado siglo y en el que el mestizo constituye el ideal de "mexicano" (Mercado, 2013, p. 11). Como se ha expuesto previamente, el surgimiento de los Estados-nación modernos supuso un proceso de homogeneización étnica, que en el caso de México implicó el mestizaje como modelo identitario de la nueva nación, de manera que no se respetó la diversidad cultural de sus múltiples pueblos originarios que han acabado excluidos (Mercado, 2013).

El caso que se presenta a continuación es el de Sebastián, el menor de los once hijos de una familia mixteca de Oaxaca. Sus padres emigraron desde su pueblo natal a diferentes lugares de México hasta llegar a Ensenada, donde él nació. Más tarde migrarían a Tijuana y, finalmente, cuando tenía entre siete u ocho años, a EUA. Permaneció indocumentado por cinco o seis años, pero en la actualidad cuenta con estatus de residente permanente y dentro de poco podrá optar por la ciudadanía.

Esta experiencia de vida y de migración interna, en México, e internacional hacia EuA, le ha hecho experimentar la otredad tanto en su país de origen como en el que lo recibió cuando aún era un niño. Sobre su experiencia de sentirse "otro" afirma lo siguiente:

Sebastián, 31 años, generación 1.5:

Cuando estábamos fuera del pueblo, en México, eran los indios, y aquí, en Estados Unidos, también lo somos... No somos parte de la cultura principal [...] lo tuve que aceptar. Aunque yo no me puedo asimilar fácilmente porque soy muy prieto $[\ldots]$ y ahora que lo acepto, lo celebro $[\ldots]$ me siento muy a 
gusto en mi piel, estoy aprendiendo a dominar mi piel (Sebastián, entrevista, 20 de junio de 2016).

Para Sebastián, su otredad reside en una cuestión cultural pues, según afirma, "nunca han formado parte de la cultura principal", ni en México ni en EuA. Y seguidamente afirma que el fenotipo, concretamente el color de su piel, constituye el principal impedimento para asimilarse, para borrar esa diferencia. Por tanto, para Sebastián y su familia la exclusión y la discriminación ha sido una constante a ambos lados de la frontera. De esta manera, tiene lugar un doble límite étnico, como indígena mexicano frente al mexicano mestizo y como mexicano respecto al americano "WASP". En este sentido, su relato refleja el racismo y la discriminación estructural que sufren los grupos indígenas en ambos contextos nacionales. En el caso de México, la Encuesta Nacional sobre Discriminación en México (Consejo Nacional para Prevenir la Discriminación, 2010) recoge los principales problemas que la población indígena identifica como propios, entre los que la discriminación, con casi 20\%, ocupa el primer lugar, seguido de la pobreza y el apoyo del gobierno, con $9.4 \%$ y $8.8 \%$, respectivamente.

Alicia también hace referencia a su indigeneidad, ya que se autoidentifica con los wixáricas, grupo étnico que habita en el lugar de origen de sus padres, Zacatecas. Sin embargo, su situación es muy diferente a la de Sebastián, ya que para ella la relación con sus ancestros indígenas está basada en una relación imaginaria y simbólica, la cual también ha estado presente en los relatos de otros informantes.

Alicia, 23 años, generación 2.0:

A nosotros nos consideraron blancos cuando se apartaron México de Estados Unidos, pero, luego, hay unos que se ven blancos y otros negros. La palabra con la que sí me identifico sería huichol porque mis raíces van a los indígenas huicholes, que van a Jerez, de donde son mis papás (Alicia, entrevista, 2 de junio de 2016).

Stuart Hall (1996) refería que la representación constituye un aspecto fundamental de las identificaciones. Y debido al proceso de reconstrucción en el que se halla inmersa abarca tanto la tradición como su reinvención, por ello, "lo imaginario", "lo simbólico" y lo fantástico constituyen componentes intrínsecos de este proceso (Hall, 1996, p. 18). Por tanto, los fragmentos de los relatos de los jóvenes aquí expuestos dejan constancia de que sus autoidentificaciones están lejos de unificarse y dan lugar a procesos que se construyen y reconstruyen una y otra vez, "de múltiples maneras a través de discursos, prácticas y posiciones diferentes, a menudo cruzados y antagónicos” (Hall, 1996, p. 17).

\section{Conclusiones}

A lo largo de este trabajo se ha pretendido responder al objetivo planteado, explorar las autoidentificaciones étnicas de los jóvenes de segunda generación de origen mexicano. A través de los relatos de los jóvenes se ha constado que sus procesos de autoidentificación étnicas están en estrecha relación con algunas de las hipótesis plausibles en este trabajo, esto es el imaginario social compartido sobre el mexicano, definido como "el otro" frente al ideal de estadounidense; y cómo, a su vez, las categorías que estos jóvenes utilizan para autoidentificarse forman parte de algunas de 
las institucionalizadas por el Censo de EuA y/o le atribuyen algunos de los significados que dichas categorías llevan implícitas.

Aunque la representación de los jóvenes migrantes ha sido mínima en cuanto a los relatos presentados, se perciben algunas diferencias entre sus relatos y los de los nativos, pues son aquellos quienes en mayor medida tienden a identificarse como mexicanos, bajo el argumento de que han nacido en México; mientras que los jóvenes nacidos en EUA, es decir, los pertenecientes a la generación 2.0, son los que presentan autoidentificaciones más diversas y complejas. Desde la más repetida como es la de méxico-americano, pasando por la de latino/hispano, chicano, hasta la de nativo-americano, entre otras. Por tanto, son los nativos quienes se autoidentifican con categorías más variadas, complejas y cambiantes a lo largo del tiempo (Portes \& Rumbaut, 2010).

Sin embargo, todos los jóvenes, independientemente de que sean inmigrantes o nativos, presentan un aspecto en común, esto es, ninguno se ha autoidentificado con la categoría de "americano" o con alguna otra que haga referencia a la misma. Todas las autoidentificaciones hacen referencia a un sentimiento de pertenencia a un grupo, ya sea hispano-latino, mexicano o méxico-americano, lo que demuestra "la autoconciencia étnica". Al mismo tiempo, todas las categorías cuentan con componentes que las definen en oposición al "americano", elementos que suelen coincidir con aspectos raciales y/o fenotípicos más que con aspectos culturales. Y tampoco se debe obviar la conexión que suele establecerse con la familia o el lugar de origen. Pertenencias imaginarias de un origen compartido, donde el lugar de nacimiento del entrevistado, de sus padres o de algunos de sus antepasados se convierte en elementos de gran peso en las autoidentificaciones étnicas y nacionales (Portes \& Rumbaut, 2010).

En definitiva, las diferentes autoidentificaciones por los informantes no hacen sino corroborar algunas de las conclusiones a las que llegaron Portes y Rumbaut (2010), quienes aludían a que los jóvenes de origen mexicano nacidos en EuA son los que, en su mayoría, tienden a identificar su origen mexicano con la cuestión racial. Los autores ven en estas afirmaciones los resultados de categorías fabricadas en EUA, donde cada origen nacional tiene su correspondiente racial; con las que, además, muchos jóvenes no se sienten cómodos. En este sentido, no hay que olvidar que la mayoría de los latinos tiende a asociar el origen latino/hispano con una categoría racial específica. De ahí, que muchos no se sientan identificados con las categorías raciales presentadas por el Censo de EuA. Dos tercios de los latinos identifican "ser hispano" como parte de su cuestión racial; en el censo de 2010, los latinos fueron los que en mayor medida no se sentían identificados con los grupos raciales proporcionados en el cuestionario, de ahí que contestaran "otro grupo racial", en el que se describían como mexicano, hispano, o latinoamericano. Los resultados arrojados por el último censo de 2010 mostraron que para la mayoría de los latinos la identidad hispana es multifacética y multidimensional. Unos la definen por el país de origen de su familia, así es para los mexicanos, los cubanos y los dominicanos; mientras que otros la asocian a una identidad panétnica que consiste en resaltar los elementos en común de los latinos dentro de su diversidad (Parker et al., 2015).

De esta manera, el reconocimiento oficial de las cuestiones étnicas y raciales en EUA implica una jerarquización con base en la distancia establecida respecto al anglosajón, lo que constituye la base del modelo identitario "americano" (García Borrego, 2008). Por tanto, la etnicidad no es una realidad objetiva sino objetivada a través de las relaciones de dominación establecidas a lo largo de la historia entre euA y México 
(García Borrego, 2008). Por ello, aunque la ciudadanía estadounidense se base en el ius soli, lo que tiene como resultado que personas de diferentes "razas" y "orígenes étnicos" formen parte del mismo Estado-nación; en la cuestión étnica parece regir el ius sanguinis, pues, aunque los ciudadanos cuenten con los mismos derechos y obligaciones, la cuestión fenotípica rige en detrimento de los no blancos, en este caso de los hispanos/latinos.

\section{Referencias}

Alba, R. \& Nee, V. (1997). Rethinking Assimilation Theory for a New Era of Immigration. The International Migration Review, 31(4), 826-874.

Alba, R. \& Nee, V. (2003). Remaking the American Mainstream: Assimilation and Contemporany Immigration. Harvard University Press.

Aparicio, R. (2007). Las "segundas generaciones" en España: marroquíes, dominicanos, peruanos. Cuadernos Europeos de Deusto, (36), 19-56.

Arendt, H. (2009). Escritos judíos. Paidós.

Barth, F. (Comp.). (1976). Los grupos étnicos y sus fronteras: La organización social de las diferencias culturales. Fondo de Cultura Económica.

Bertaux, D. (1999). El enfoque biográfico: Su validez metodológica y sus potencialidades. Proposiciones 29, 1-23.

Bertaux, D. (2005). Los relatos de vida. Perspectiva etnosociológica. Ediciones Bellaterra.

Comaroff, J. \& Comaroff, J. L. (1992). Theory, ethnography, historiography. San Francisco, Oxford: Westview Press, Boulder.

Consejo Nacional para Prevenir la Discriminación. (2010, abril). Encuesta Nacional sobre Discriminación en México. http://www.conapred.org.mx/index.php?contenido=pagina\&id $=424 \&$ id_opcion $=436 \&$ cop $=436$

Denzin, N. K. (1970). The Research Act. Aldine.

Durand, J. (2017, 16 de abril). De migrantes a criminales. La Jornada en línea. https:// www.jornada.com.mx/2019/04/14/opinion/013a2pol

Ennis, S., Ríos-Vargas, M. \& Albert, N. G. (2011). The Hispanic Population: 2010. U.S. Department of Commerce, Economics and Statistics Administration, U.S. Census Bureau. https://www.census.gov/library/publications/2011/dec/c2010br-04. html

Epstein, A. L. (2006). Etnicidad e identidad. En M. Camus (Coord.), Las ideas detrás de la etnicidad. Una selección de textos para el debate (pp. 86-116). Centro de Investigaciones Regionales de Mesoamérica.

García Borrego, I. (2008). Herederos de la condición inmigrante: Adolescentes y jóvenes en familias madrileñas de origen extranjero (tesis de doctorado). Universidad Nacional de Educación a Distancia. http://espacio.uned.es/fez/eserv/tesisuned:CiencPolSoc-Igarcia/Documento.pdf

Geertz, C. (1973). La interpretación de las culturas. Gedisa.

Hall, S. (1996). Introducción ¿Quién necesita "identidad"? En S. Hall \& P. du Gay (Comps.), Cuestiones de identidad cultural (pp. 13-39). Amorrortu editores. 
Hixson, L., Hepler, B. B. \& Ouk Kim, M. (2011). The White Population: 2010. U.S. Department of Commerce, Economics and Statistics Administration, U. S. Census Bureau. https://www.census.gov/library/publications/2011/dec/c2010br-05. html?sec_ak_reference=18.0519ae8c.1581537036.14b8cd77

Huntington, S. (2004). El reto hispano. FP: Foreign Policy-Edición Española, (2). https:// www.ulima.edu.pe/sites/default/files/page/file/el_reto_hispano.pdf

Mercado, A. (2013). Subtractive citizenship and transnational indigenous resistance: Indigenous Mexicans in San Diego. Journal of Transborder Studies. Research and Practice.

Omi, M. \& Winant, H. (2015). Racial formation in the United States. Routledge.

Parker, K., Menasce, J., Morin, R. \& Lopez, M. H. (2015). Chapter 7: The Many Dimensions of Hispanic Racial Identity. Pew Research Center https:/ / www.pewsocialtrends.org/2015/06/11/chapter-7-the-many dimensions-of-hispanic-racial-identity/

Perlman, J. \& Waldinger, R. (1997). Second generation decline? Children of immigrants, past and present. A reconsideration. International Migration Review, 31(4), 1415-1430. https://doi.org/10.1177\%2F019791839703100405

Portes, A. \& Rumbaut, R. G. (2010). Legados. La historia de la segunda generación inmigrante. Hipatia.

Portes, A. \& Zhou, M. (1993). The new second generation: Segmented assimilation and its variants. Annals of the American Academy of Political and Social Science, 530(1), 74-96. https://doi.org/10.1177\%2F0002716293530001006

Rastogi, S., Johnson, T. D., Hoeffel, E. M. \& Drewery, M. P. (2011). The Black Population. U.S. Department of Commerce, Economics and Statistics Administration, U.S. Census Bureau. https://www.census.gov/library/publications/2011/dec/ c2010br-06.html

Rumbaut, R. G. (2006). Edades, etapas de la vida y cohortes generacionales: Un análisis de las dos primeras generaciones de inmigrantes en Estados Unidos. En A. Portes \& J. DeWind (Coords.), Repensando las migraciones. Nuevas perspectivas teóricas y empíricas. (Colección América Latina y el Nuevo Orden Mundial, pp. 361-409). Miguel Ángel Porrua/uAz/Secretaría de Gobernación/Instituto Nacional de Migración.

Saraví, G. A. (2015). Juventudes fragmentadas. Socialización, clase y cultura en la construcción de la desigualdad. ciesas/Flacso México.

Trevelyan, E., Gambino, C., Gryn, T., Larsen, L., Acosta, Y., Grieco, E., Harris, D. \& Walters, N. (2016). Characteristics of the U. S. Population by generational status: 2013. U. S. Department of Commerce, Economics and Statistics Administration. U. S., Census Boureau. https://www.census.gov/library/publications/2016/demo/p23-214.html

Wimmer, A. \& Glick Schiller, N. (2002). Methodological nationalism and beyond: Nation state building, migration and the social sciences. Global Networks, 2(4), 301-304. 
María del Rosario Narváez Jiménez

Española. Doctora en ciencias sociales por la Universidad Autónoma del Estado de Morelos. Maestra en comunicación y cultura por la Universidad de Sevilla. Licenciada en antropología social y cultural por la Universidad Nacional de Educación a Distancia. Licenciada en sociología por la Universidad de Granada. Universidad Autónoma del Estado de Morelos. Líneas de investigación: juventudes, niñez y migración internacional. Publicación reciente: Narváez Jiménez, M. R. (2020). Testimonios fotográficos de la pandemia por covid-19. Antrópica. Revista de Ciencias Sociales y Humanidades, 6(6), 32-33. 